\title{
When the sky fell in on the dinosaurs
}

\section{T. rex and the Grater of Doom}

by Walter Alvarez

Princeton University Press: 1997. Pp. 185. \$24.95, $£ 18.95$

\section{Clark R. Chapman}

While the theories of plate tectonics were being developed in the 1960s, the Apollo missions revealed the ubiquitous planetary cratering that would eventually lead to another revolution in geology - the recognition that impacts by asteroids and comets have helped to shape the Earth's surface and influenced the evolution of life. Walter Alvarez contends in this slim book that the excitement of plate tectonics distracted most geologists from the lessons coming from space. Not until 1980, when Alvarez, his father and some colleagues published their paper proposing an extraterrestrial cause for the Cretaceous/Tertiary (K/T) mass extinctions, were geologists forced to confront cosmic catastrophism.

It has been a painful conversion for most geoscientists, because impacts were considered to be antithetical to the uniformitarian dogma that had dominated geology for two centuries, including the view that climate changes or a fall in sea level led to the mass extinctions. The tale of the heated debates in the 1980s about the Alvarez hypothesis is not fully told in this book, despite the promise on the dust cover that it recounts "intense public debate [and] friendships made or lost...". Although he writes of friendships made during field trips in dis-

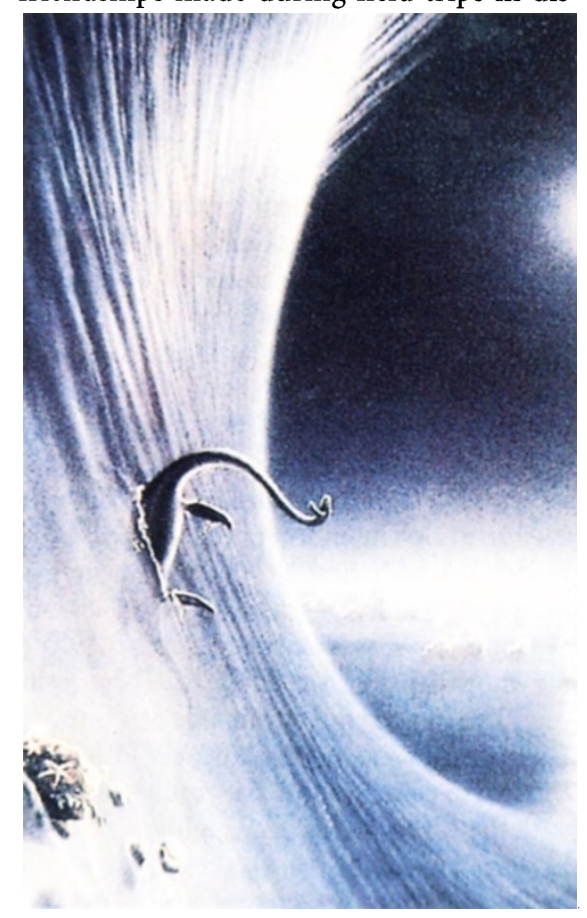

...creating a giant sea wave that sweeps the dinosaurs to their doom.

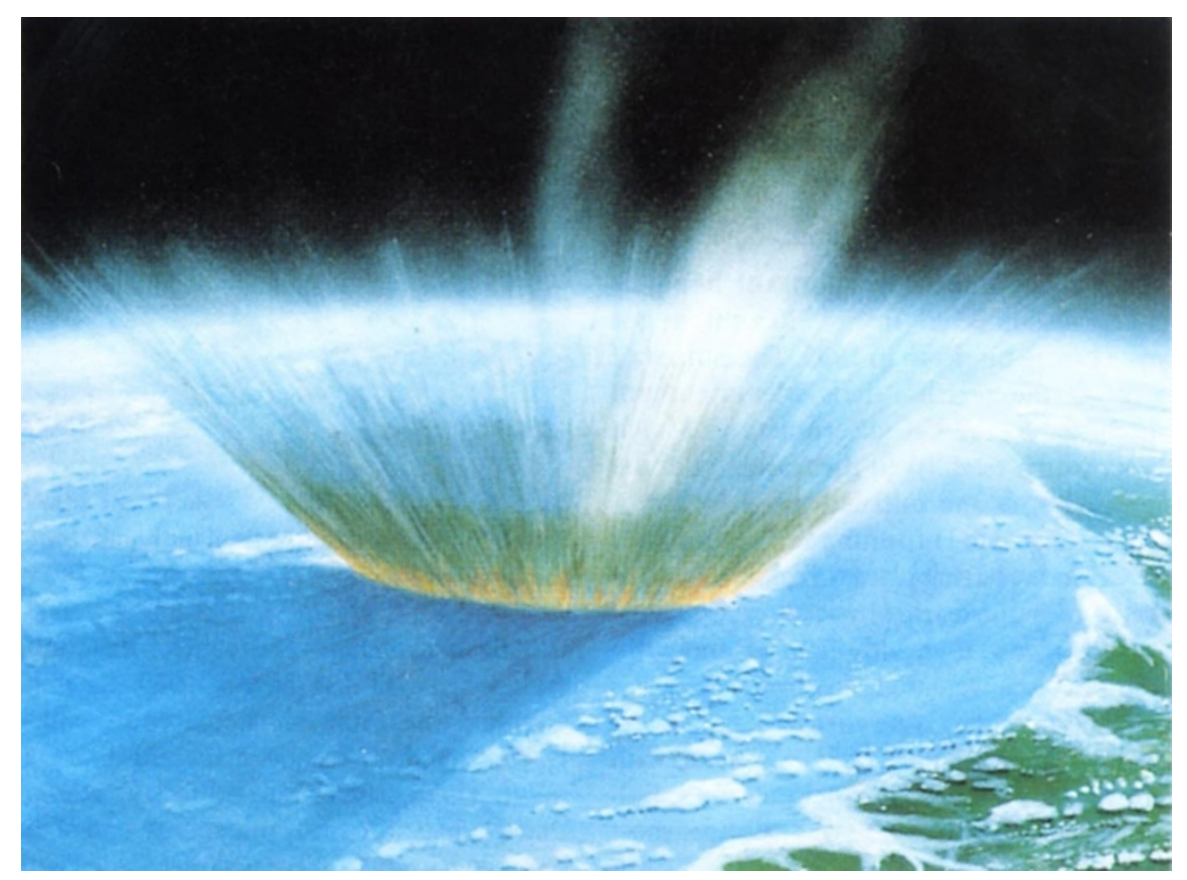

Moment of impact: a comet or asteroid at least $10 \mathrm{~km}$ wide hits the Earth...

tant lands, Alvarez is too civil to delve deeply into the rivalries, media mistakes, public antagonisms or friendships lost.

The book has a simpler, yet fascinating story to tell - that of how Alvarez's geological career led him to study the $\mathrm{K} / \mathrm{T}$ boundary layer at Gubbio, Italy, and how the immense Chicxulub crater was located in the Yucatán Peninsula, Mexico, seeming to prove his father's idea that global dust from an impact led to the holocaust 65 million years ago. The tale is personal, well written and delightful. Alvarez also reflects on the history and philosophy of geology, making this book well suited to geology students and literate non-geologists interested in how geologists think.

Alvarez portrays a modern geology that builds on the interdisciplinary resources of physics, chemistry and astronomy to fashion a synthesis about how our planet has evolved.

Discovery of the famous iridium anomaly in the K/T boundary layer appears part of the way through the book, beginning the mystery story about the hunt for the "crater of doom". Although he gives credit where credit is due, this is primarily the story of Alvarez's own quest for the answer, involving both miscues and suc-cesses, finally focusing on the 65-million-year-old Mexican crater.

We read of tsunami deposits in Texas and Haiti, geophysical identification of the buried crater in the Yucatán, discovery of microtektite spherules in the boundary layer, and the discovery and dating of melt rocks. Strangely, Alvarez's personal turning point came later, in 1992: he tells of a moment of epiphany in the central plaza of a small Mexican town.

Sticking close to his own role and expertise, Alvarez omits other elements of the $\mathrm{K} / \mathrm{T}$ story. His father's idea that the dinosaurs, at the top of the food chain, died from starvation because of the collapse of photosynthesis during year-long darkness is introduced but never analysed. He does not discuss (except in a prologue) the many other environmental consequences of impacts that have been researched during the past 15 years. Much of the antagonism of palaeontologists to the Alvarez idea that the dinosaurs died out suddenly is caused by their inability to reconcile ostensible killing mechanisms with the fossil record. Yet Alvarez does not choose to try to address their concerns here.

Towards the end of the book, Alvarez mentions without amplification a few unresolved issues, such as whether other mass extinctions in the geological record might have been caused by impacts. $\mathrm{He}$ closes with a brief reflection on the symbolism of the crash of comet ShoemakerLevy 9 into Jupiter.

One can read T. rex and the Crater of Doom in a single sitting and I recommend it highly - if only as a jumping-off point to other perspectives on this dramatic scientific revolution.

Clark R. Chapman is at the Southwest Research Institute, 1050 Walnut Street, Boulder, Colorado 80302, USA. 